\title{
MÉXICO A TRAVÉS DE LOS OJOS DEL WALL STREET JOURNAL: IMÁGENES DE UNA NACIÓN Y DE UN ACUERDO ECONÓMICO (1993 - 1994)
}

\author{
Itziar Vañó de Urquijo \\ IIDL - Universidad de Valencia \\ Investigadora predoctoral (FPU) \\ Contacto: Itziar.Vano@uv.es
}

Fecha de recepción: 15/09/2015

Fecha de aceptación: 01/12/2015

\begin{abstract}
Resumen
El artículo estudia la visión sobre México presentada en el diario económico estadounidense The Wall Street Journal durante los años 1993 y 1994, coincidiendo con la aprobación y entrada en vigor del Tratado de Libre Comercio de América del Norte. Se muestran, a través de un análisis del discurso y de contenidos, la complejidad y las contradicciones del discurso del periódico, así como la evolución de la imagen de la nación mexicana en el tiempo estudiado, a caballo entre lo marcado por la línea editorial del periódico (la defensa del Tratado y la imagen ad hoc de México) y por los acontecimientos políticos, económicos y sociales del país.
\end{abstract}

Palabras clave: Estados Unidos; México, TLC;Wall Street Journal; percepciones.

MEXICO THROUGH THE EYES OF THE WALL STREET JOURNAL: IMAGES OF A NATION AND ECONOMIC AGREEMENT (1993 - 1994).

\section{Summary}

The article examines the vision of Mexico portrayed in the US financial newspaper The Wall Street Journalfrom 1993 to 1994, coinciding with the passing and enforcement of the North American Free Trade Agreement. The article shows both the complexity and contradictions found in thenewspaper's discourse, as well as the changes in the image of Mexico built by the newspaper. This image evolves from an optimistic perspective derived from the Journal's editorial line (a strong supporter of the Trade Agreement) to a more pessimistic one led by the troubling social, political and economic events of 1994.

Key words: États-Unis ;Mexique; Accord de Libre Échange;Wall Street Journal; perceptions.

MEXIQUE PAR LES YEUX DU WALL STREET JOURNAL: IMAGES D'UNE NATION ET ACCORD ÉCONOMIQUE (1993 - 1994).

\section{Résumé.}

L'article examine la vision du Mexique interprété dans le quotidien financier américain The Wall Street Journal pendant les années 1993 et 1994, coïncidant avec l'adoption et l'application de l'Accord de Libre Échange nord-américain. L'article montre à la fois la complexité et les contradictions du discours du journal, ainsi que l'évolution de l'image de la nation mexicaine, à mi-chemin entre ce qui est marqué par la ligne 
éditoriale du journal (la défense du traité et l'image ad hoc du Mexique) et le résultat de la vision des développements politiques, économiques et sociaux dans le pays.

Mots-clés: États Unis; Mexique, TLC; Wall Street Journal; perceptions.

\section{INTRODUCCIÓN}

El presente artículo tiene como objetivo analizar la imagen que el diario económico estadounidense The Wall Street Journal construyó sobre el vecino México durante el período de aprobación y puesta en marcha del Tratado de Libre Comercio (TLC, TLCAN o Nafta) firmado por ambos países (junto con Canadá) en los años noventa. En él estudiamos cómo percibía EE.UU. a México y a los mexicanos, qué decía de ellos, cómo construyó esa imagen de lo ajeno y la articuló a través del discurso público. Diferentes autores subrayan el importante papel que los prejuicios y estereotipos juegan en la toma de decisiones políticas o económicas (Anderson, 2008), idea que resulta clave para entender la relevancia de estudiar un medio de comunicación como el WSJ.

En el trabajo reflexionamos también sobre la capacidad de estas percepciones para perpetuarse y el grado de rigidez o flexibilidad que presentan, viendo si el impacto del acuerdo comercial fue capaz de alterar el discurso sobre México. Un discurso que, a nuestro juicio, revela tanto sobre los propios estadounidenses como sobre la realidad mexicana. De los artículos analizados se desprende un concepto determinado de nación, fundamentado en la superioridad cultural y económica que los estadounidenses se atribuyen, y del que puede deducirse una concepción del mundo basada en la dicotomía desarrollo-subdesarrollo, con poco espacio para los matices y centrada casi exclusivamente en los indicadores económicos. Una dicotomía que el Wall StreetJournal tratará de trascender en algunos momentos pero que, argumentamos, no será capaz de erradicar.

En todo el período analizado (1993-1994) México oscila entre los dos polos, el de la nación desarrollada que aspira a ser y la nación subdesarrollada que, a ojos de USA, todavía es. Como punto de inflexión aparece el Tratado de Libre Comercio, que el diario considera crucial para transformar la realidad del país vecino a pesar de la oposición de gran parte de la sociedad norteamericana. Esa capacidad transformadora y esa aparente búsqueda de beneficios y desarrollo para la sociedad vecina llevan aparejados una enorme carga de intereses particulares que también van haciéndose evidentes en el análisis de la publicación.

Se construye, en definitiva, la imagen de una nación vecina ex profeso para servir al propósito de la publicación estadounidense, que abogó por la aprobación del tratado económico de forma muy activa, sirviendo de plataforma de difusión del ideario conservador librecambista.

Ese proceso de construcción de imágenes de lo extranjero para servir a los intereses de la propia nación no es exclusivo de los Estados Unidos, sino que se emplea como herramienta habitual en la construcción y mantenimiento de los estados-nación. Sin embargo, la relación y concepción mutua entre México y Estados Unidos representan un caso especial por la relevancia internacional de ambos países. EE.UU., no cabe duda, sigue 
siendo una potencia fundamental en estos inicios del siglo XXI, a pesar de la transición de un mundo de dos bloques a uno más policéfalo. $Y$ México, a pesar de los problemas que arrastra, es, por población, peso económico e influencia cultural, una de las principales potencias de América Latina.

Pero su relevancia deriva sobre todo de la estrecha relación (más o menos conflictiva) que provoca el vivir cada uno en un lado de la misma frontera. Una frontera fluida si atendemos a la población de origen mexicano que vive hoy en Estados Unidos o a la cultura de consumo mexicana que coloca en un pedestal cualquier producto que proceda del vecino del norte. Decía Hobsbawm en su Sobre la historia que las innovaciones se cuelan por los intersticios de la historia (Hobsbawm, 1998: 24). Es a través de lo cotidiano como se van construyendo, transformando y actualizando las relaciones. Sin embargo, los discursos y las percepciones son a veces más difíciles de alterar, pues no se basan completamente en la realidad de lo cotidiano sino que heredan elementos ya prefigurados, se insertan en una tradición. A la imagen del otro se le van sumando elementos que permiten hacerla comprensible a los ojos de uno y que consiguen encajarla en las categorías de pensamiento conocidas. De ahí que la dicotomía nosotros/ellos sea tan exitosa. Simplifica lo complejo, ofrece la seguridad de lo conocido.

Tanto México como Estados Unidos han empleado en su proceso de construcción de la identidad nacional esta herramienta de la caricatura simplista. El Wall Street Journal ofrece un discurso mucho más complejo, aunque inevitablemente bebe de esta tradición.

Nuestro trabajo se inserta, desde la historia del tiempo presente, en esta corriente que estudia los procesos históricos de construcción de imágenes/percepciones. Esperamos que contribuya, en su humilde medida, a una mejor comprensión de la historia reciente de ambas naciones, así como al estudio de las dinámicas generales que se establecen entre naciones que se embarcan en acuerdos comerciales partiendo de niveles de riqueza desiguales. O que sirva, quizá, para acercarnos a nuestro presente, puesto que nos permite reflexionar sobre las consecuencias del TLCAN justo cuando otro acuerdo económico, el TTIP, está siendo negociado entre Estados Unidos y la Unión Europea. Quizá las lecciones del primero, a pesar de las diferencias entre los firmantes de cada uno, sirvan para comprender y abordar mejor el actual.

\section{METODOLOGÍA}

La selección del Wall Street Journal ${ }^{1}$ como objeto de estudio obedece a razones de difusión, prestigio e influencia. Es la publicación más leída en Estados Unidos, incluso por encima de la prensa generalista. ${ }^{2}$ En los años 90 tenía unas ventas estables de en torno a 1,8 millones de ejemplares (Arrese, 2002: 290).

\footnotetext{
${ }^{1}$ Diario económico radicado en la ciudad de Nueva York (aunque con distribución internacional). Fundado por Charles H. Dow y Edward D. Jones en 1889. Publicado por la Dow Jones \& Company, que desde 2007 pertenece al grupo News Corporation.

${ }^{2}$ El Wall Street Journal, periódico más leído del país, sólo se publica de lunes a sábado. The New York Times todos los días de la semana, siendo el más leído del domingo.Fuente: Alliance for Audited Media. Tabla 2 (la número 1 corresponde únicamente a la edición dominical), datos de marzo de 2013. http://www.auditedmedia.com/news/research-and-data/top-25-us-newspapers-for-march-2013.aspx
} 
Además, para la última década del siglo, "el prestigio y la autoridad del Journal, en esta época bajo la dirección de Robert L. Bartley, estaban fuera de toda duda" (Arrese, 2002: 276), siendo un medio con una gran influencia a nivel nacional e, incluso, internacional.

La muestra estudiada corresponde a los números publicados entre enero de 1993 y diciembre de 1994 en la edición estadounidense del diario. El acceso a los fondos hemerográficos del WSJ se ha realizado a través de Factiva, una de las mayores bases de datos para prensa, que además pertenece a la Dow Jones \& Company, la compañía editora del Wall Street Journal. Para sistematizar el trabajo, se ha realizado un rastreo empleando Mexico como término de búsqueda (ver gráfico 1), aunque a lo largo de la investigación hemos empleado palabras clave complementarias (Nafta, bribe, corruption, Chile...) para hacer comprobaciones y completar alguna información.

Gráfico 1. Resultados de búsqueda del término "Mexico" en el Wall Street Journal (enero 1993 - diciembre 1994).

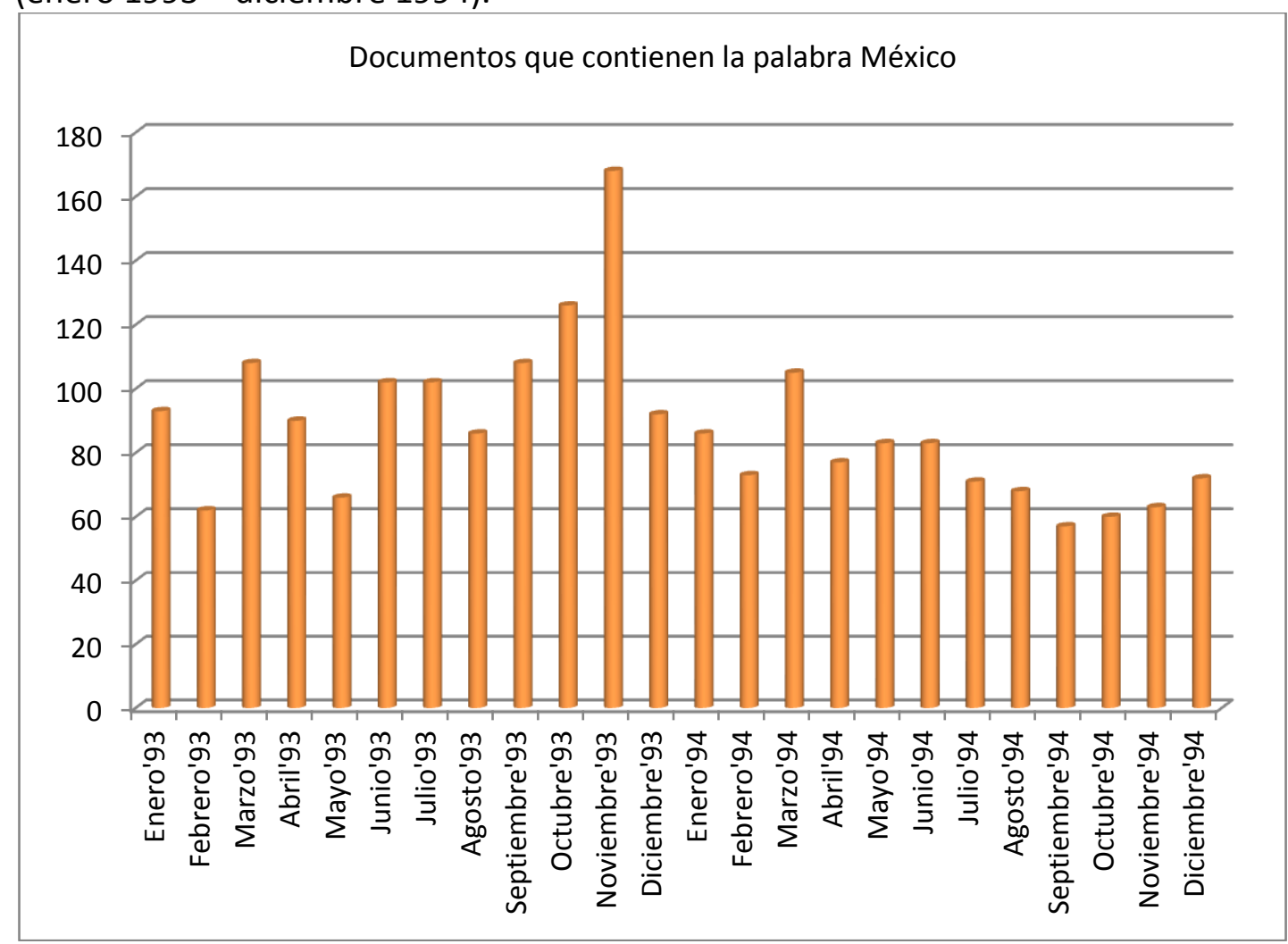

Fuente: Elaboración propia con datos de Factiva.

Desde el 1 de enero de 1993 hasta el 31 de diciembre de 1994, el Wall Street Journal publicó 2101 noticias, artículos, reportajes, etc. que contenían la palabra México en su texto. Como vemos, el número de resultados obtenidos es mayor durante el año 93, con un total de 1203 coincidencias. El máximo absoluto de la tabla corresponde a noviembre de 1993, mes en que el Congreso de EE.UU. ratificó la firma del TLC. Para el año 94 encontramos 898 resultados, con un máximo relativo correspondiente al mes de 
marzo, consecuencia del asesinato del candidato a la presidencia de México Luis Donaldo Colosio.

De la búsqueda sistemática inicial se hizo una primera criba, excluyendo las referencias a Nuevo México o al Golfo de México, que representan de media en torno al $15 \%$ del total. La segunda fase consistió en un análisis somero de todos los documentos seleccionados para distribuirlos según su categoría. Establecimos dos grandes grupos: por un lado, documentos de carácter menos valorativo; por otro, aquellos susceptibles de ser estudiados en profundidad, para los que optamos por un método de análisis de contenidos y del discurso mucho más exhaustivo.

Al primer grupo que hemos mencionado pertenecen fundamentalmente documentos de cuatro categorías: los Publicly Traded Funds, los Closed End Funds, la sección Business and Finance y los Business o Marketing Briefs. Los dos primeros, referidos a datos bursátiles y fondos de inversión, se han tenido en cuenta tan sólo a nivel cuantitativo. Los Business Briefs y los Marketing Briefs, además de la sección Business and Finance, son noticias breves de temática económica. Hemos tratado de buscar tendencias o patrones comunes para extraer conclusiones generales, valorando por ejemplo los momentos en que abundan las noticias positivas (inversiones, inicio de empresas conjuntas...) frente a los períodos en que son más comunes las negativas (negociaciones frustradas, empresas que fracasan...).

La tercera fase de estudio corresponde al análisis exhaustivo de los documentos más relevantes, aquellos que en la fase anterior habíamos agrupado separadamente. En este grupo hemos incluido las noticias breves de la sección What's news - World wide, noticias de mayor longitud, reportajes, editoriales (llamados Review \& Outlook), artículos de opinión (destacan los op-ed y la columna The Americas) y cartas al editor. Este grupo de documentos es el que constituye el grueso de nuestro estudio. Encontramos, por una parte, las noticias o artículos referidos a la evolución del proceso de aprobación del TLC en el Congreso durante el año 1993 y las de su puesta en marcha durante el 94. Por otra parte, aparecen noticias o reportajes que dan a conocer al público estadounidense la realidad política y socioeconómica de la nación mexicana. Destaca la clara orientación de la línea editorial a favor del libre comercio, así como el prestigio de las firmas invitadas. Para el análisis de estas secciones hemos empleado una metodología descriptiva centrada no tanto en los hechos en sí como en la forma que el periódico tiene de presentarlos y la perspectiva desde la que lo hace, enfocándonos en la imagen de México que se construye desde el periódico.

\section{RESULTADOS}

A continuaciónpresentamos los resultados de la investigación. Los dos primerossubapartadossiguen un ordencronológico, mostrando el fuerte contraste entre el año 1993 y los resultadosarrojados para el año 1994. El tercer subapartadoofreceunaperspectivaregional, comparando las experiencias de los estadosfronterizos de Texas y California en los dos añosestudiados (1993-94), pues en las experiencias locales se observanprácticas que divergen de las tendenciasnacionales. 


\subsection{3 y la lucha por la aprobacióndel TLC}

Durante el año 1993 el Wall Street Journal publicó más de mil documentos que contenían el término Mexico. Aunque bastante repartidas durante todo el año, se observa una mayor concentración en los meses de octubre y noviembre, coincidiendo con la proximidad de la votación en el Congreso de Estados Unidos para ratificar la firma del TLC (que se produjo finalmente el 17 de noviembre).

Desde inicios de año aparecen ya numerosos artículos que van narrando la evolución de los preparativos para la puesta en marcha del Tratado (negociación de los acuerdos complementarios, discusiones de los legisladores y otros actores políticos sobre la conveniencia o no de ratificarlo...). Acompañando este proceso observamos un progresivo incremento del número de noticias y reportajes que presentan al lector del diario las oportunidades económicas del país, poniendo ejemplos de grandes empresas y emprendedores que ya han decidido invertir o trabajar en México, así como otros que dan a conocer la realidad político-social y las costumbres del país.

El Wall Street Journal no sólo se encargó de visibilizar el debate, de colocarlo en la agenda política, sino que se posicionó activamente a favor de la aprobación del TLC y sirvió de plataforma a economistas, políticos y empresarios conservadores para compartir en las páginas del diario su opinión sobre los beneficios que reportaría a los norteamericanos. Ante la existencia de otros asuntos internacionales (Bosnia y Somalia, principalmente) que "absorbían" a la opinión pública estadounidense (Weiner, 1993), el WSJ hizo un esfuerzo por poner México y el debate en el mapa mediático.

La necesidad de esta campaña intensiva a favor del tratado vino dada por las enormes dudas sobre los apoyos con los que contaba realmente el TLC en el Congreso. Un buen reflejo de los obstáculos a los que se enfrentó la iniciativa legislativa en los meses previos nos lo da la propia distribución de los votos en la cámara: a favor votaron 102 demócratas y 132 republicanos, en contra 156 demócratas, 43 republicanos y un independiente. Es decir, que el presidente Clinton tuvo que convencer a su propio partido de las bondades del TLC, además de a sí mismo, ya que durante la campaña electoral de 1992 contra Bush y Perot se había opuesto. Tras asumir el cargo de presidente Clinton modificó su postura respecto al TLC, aunque exigía pactos paralelos en materia ecológica y laboral (Solís, 1993a) y su administración daba signos de vacilación demasiado desconcertantes para muchos periodistas y colaboradores del diario.La columna editorial del WSJ fue constante exigiendo mayor compromiso y decisión por parte del mandatario: "the world could use a strong signal that the U.S. President is unambiguously committed to an open trading system" (Editorial I, 1993).

Para muchos demócratas el plan respondía a una política de carácter conservador, propia del partido republicano. Para Clinton, la defensa del Nafta supuso un riesgo político. Apoyar un tratado que eliminaba las barreras para el paso de mercancías y capital (no de personas) suponía enfrentarse a los sindicatos más poderosos del país (fuente de fondos y votos), que veían en este acuerdo internacional un peligro potencial, puesto que 
consideraban que destruiría miles de puestos de trabajo y gran parte del tejido industrial del país al trasladarse las empresas a México.

Una de las principales críticas de los sindicatos era la laxa regulación laboral que establecía el Tratado (firmado en diciembre de 1992, pendiente de ratificación), dejando desprotegidos a los trabajadores estadounidenses. Los empresarios, aseguraban los sindicatos, preferirían trasladarse a México, donde apenas existían derechos para los trabajadores. Además, los sindicatos alegaban estar defendiendo también los derechos de los trabajadores mexicanos. Todo esto les condujo a oponerse a su ratificación hasta que se lograran acuerdos paralelos. Frente a estos argumentos, el WSJ fue tajante en defender el sistema laboral mexicano. Aunque se reconoce un problema de eficacia a la hora de aplicar la ley, se contextualizan esas supuestas lagunas legales, atribuyéndolo a la cultura mexicana, basada más en los derechos consuetudinarios y en los acuerdos entre empresario y trabajadores, lo que responde a su propia realidad socioeconómica. Se afirma, incluso, que superando las distancias entre ambos mercados laborales, puede observarse una mayor preocupación por los derechos de los trabajadores en México. Y, además, se cimienta esta idea en la propia historia mexicana: Mexico's dedication to workers' rights is both real and founded on deeply felt fundamental principles firmly rooted in its history, its Constitution and its Federal Labor Law. (Breger, 1993)

Las referencias a la historia mexicana varían considerablemente según el objetivo del autor del artículo. El diario muestra así ciertas contradicciones al retratar al futuro socio comercial de EE.UU., originadas siempre por la voluntad de mostrar la imagen de la nación que más le interesa en cada momento. Por un lado, era necesario retratarlo como un lugar preparado para asumir las inversiones estadounidenses, para así alentar a los empresarios que miraban con desconfianza, pues muchos creían que el país no estaba listo todavía para entrar en el acuerdo (Solís, 1993b). Pero por otro lado interesaba mostrar las flaquezas de México para disipar los temores de quienes creían que se produciría una masiva deslocalización industrial.

Ese desconocimiento de los estadounidenses sobre la realidad mexicana jugó a favor del Wall StreetJournal en lo referido a la elaboración de un discurso sobre México, pero fue un obstáculo a la hora de explicar el funcionamiento del acuerdo comercial. Por esta razón el diario a menudo empleó analogías de realidades que fueran más familiares a los lectores, siendo habituales las menciones a la Comunidad Europea, a la que se pone como ejemplo paradigmático de una "satisfactoria unión económica" incluso entre países que partían de un distinto nivel de desarrollo (Carrington, 1993).Se destaca el valor de un proyecto a largo plazo y ambicioso, aunque se insiste mucho en que, al contrario que la CE, el TLC no ambiciona adquirir una dimensión política ni alcanzar un nivel de regulación tan complejo, porque eso a la larga dificultaría el comercio (Ehrbar, 1993).

Otra de las estrategias clave del diario es apelar al compromiso histórico de Estados Unidos con la democracia. EI WSJ establece una conexión directa entre libre comercio y democracia. ${ }^{3}$ Se llega a afirmar, incluso, que el capitalismo es necesario para

\footnotetext{
${ }^{3}$ Estas teorías que relacionaban capitalismo librecambista con fortalecimiento de la democracia tuvieron gran predicamento en los departamentos de ciencia política de las universidades de Estados Unidos desde los años sesenta del siglo XX. Destaca especialmente la obra de autores como Seymour Martin LIPSET y Adam PRZEWORSKI.
} 
que exista democracia (entre otros en Rowen, 1993), de lo que se infiere que ayudar a la instauración del libre mercado en América Latina tendrá como consecuencia una mejora en la calidad democrática de estos países, siendo México el primer paso. Además, se destaca el rol de liderazgo de Estados Unidos, cuyas acciones se consideran determinantes para el resto del continente, a los que se retrata siempre buscando su aprobación. El TLC se convierte así en herramienta democratizadora: "If Nafta falters or even fails, it could cause an irrevocable rift in relations with an important neighbor, whose future is going to be either very dynamic or very volatile. It could also undermine or derail some of the dramatic economic, social and political progress made by Mexico under President Carlos Salinas's leadership. And beyond Mexico, it would demoralize Latin America generally, where democracy's recent successes depend on delivering economic benefits" [la cursiva es nuestra]. (Editorial II, 1993)

Y es que muchas veces el WSJ no consigue concebir México como un país exitoso capaz de avanzar por sus propios medios. Los prejuicios y la tradicional visión hemisférica de una América anglosajona exitosa frente a una América latina fallida emergen de vez en cuando.

Esto va ligado a una ausencia llamativa en el periódico: la de artículos o noticias que hablen de la oposición al TLC en México, cuando sí se mostraba la oposición al mismo en Canadá (entre otros: Edmonds, 1993). A nuestro juicio refleja esta idea de las dos américas, la exitosa frente a la fallida. Para los americanos es inconcebible que los mexicanos deseen conservar elementos nacionales propios, ya que se percibe a México como una nación más atrasada para la que el TLC sólo puede ser beneficioso. Las menciones a la oposición al tratado son mínimas y, cuando aparecen, siempre se achacan a un nacionalismo exacerbado, proteccionista y antiamericano.

En contraste con este vacío, las referencias a la oposición dentro de EE.UU. son constantes. El diario refleja las habituales críticas al TLC durante estos meses, aunque siempre buscando el modo de desacreditarlas. Para ello, se apoyó especialmente en los discursos de Clinton y sus apariciones públicas, sobre todo desde mediados de agosto, una vez los side-agreements estuvieron negociados y el presidente reforzó su posición sobre el TLC.

Uno de los principales esfuerzos del WSJ y del presidente se centró en atraer hacia su postura a los sindicatos, los cuales comentábamos páginas atrás que se opusieron radicalmente al Tratado y no quedaron satisfechos con los acuerdos alcanzados, lo que auguraba un difícil paso por el Congreso. Era urgente pues convencerles. El argumento de Clinton sobre la cuestión laboral, reiterado durante toda su campaña en busca de apoyos, se basaba en un polo positivo y otro negativo: el positivo sugería que, en realidad, el acuerdo comercial generaría más puestos de trabajo al abrir a las empresas norteamericanas nuevos mercados de exportación (insistiendo especialmente en la industria automovilística); pero esto venía acompañado de un argumento a modo de advertencia: no aprobar el TLC supondría dejar vía libre a otros países como Alemania para crear su propia zona de libre comercio con México, lo que sí perjudicaría a Estados Unidos a la larga (Noticia I, 1993).

Los sindicatos no fueron los únicos en oponerse al tratado. El liderazgo de la oposición al TLC lo asumió pronto Ross Perot, candidato en 1992 a la presidencia como 
independiente. Perot era también un hombre de negocios, lo que indica que existía más división sobre el pacto en los círculos financieros de la que pueda parecer a simple vista. Con una postura muy proteccionista, su rechazo se centraba en la pérdida de puestos de trabajo y se complementaba con argumentos medioambientales y de defensa de los Derechos Humanos. Aunque el Wall Street Journal recoge también las opiniones de Perot y otros opositores, el punto de vista de los autores de los artículos siempre parece dejar claro que se trata de una opinión insostenible e incluso interesada, en la que estos argumentos se utilizan de forma meramente instrumental: "concerns about Mexican democracy and human rights give a cover of morality and unselfishness to even the most protectionist-minded Nafta opponents" (Robbins, 1993).

Esos argumentos reflejan una tendencia habitual en la historia de Estados Unidos: la intervención en países extranjeros de forma indirecta, a través de políticas de "premios y castigos". Ahondando en una idea ya esbozada, insistimos en que USA se concibe así mismo como el país llamado a liderar el continente y considera que el resto de gobiernos utilizan la aprobación estadounidense para legitimarse. Incluso aquellos a favor del tratado reconocían el espaldarazo que el triunfo supondría para el PRI y el bache si el plan fracasaba:

There is little doubt that Nafta will strengthen Mexico's all-powerful ruling party", he says. Nafta's defeat, he acknowledges, would be a major blow for Mexican President Carlos Salinas de Gortari, who has championed the pact as key to his far-reaching economic reform plans. "But whether that defeat would be enough" to knock the ruling Institutional Revolutionary Party, or PRI, off its 60-plus year perch, "or simply undermine the reform faction inside the party, is anybody's guess."(John Bailey en Robbins, 1993)

En el fondo, este tipo de razonamientorefleja a nuestro juicio una visión del país mexicano como nación todavía en desarrollo, con un sistema escasamente democrático y fácilmente manipulable, en el que los dirigentes parecen estar más pendientes de ganar la aprobación de EE.UU. que la de la opinión pública de su propio país, porque en realidad no la necesitarían, ya que lo que sugieren muchos de los artículos es que el PRI gobierna gracias a procesos electorales algo dudosos: "the PRI is assumed to have cheated widely to win"(Carroll y Solís, 1993; refiriéndose a las elecciones generales de 1988). En esa situación, el papel de Estados Unidos se presenta como clave para que las cosas en el país funcionen o dejen de funcionar, dando a entender que no es un tratado firmado entre iguales, sino entre una nación directora (USA, con Canadá como vecino que no da problemas) y una dependiente (México), en la que la primera marcará la pauta a voluntad:

These reforms still won't alter the PRI's guaranteed dominance of Mexican politics, at least not before the U.S. decides whether closer trade ties will help or hinder democracy at our southern border (Robbins, 1993).

Pero el TLC recibía ataques desde muchos ámbitos. El argumento referente a la pobreza y las violaciones de derechos humanos en la república mexicana era difícil de 
eludir para el diario. Por un lado, se invitaba a los lectores a superar viejas visiones y actualizarlas:

Contrary to popular myth, wages and working conditions have been moving steadily upward in Mexico (...)A middle-income class is emerging in Mexico, so long afflicted by extremes of wealth and poverty (Wright, 1993).

Por otro lado, se sugería que el TLC permitiría a los Estados Unidos tener mayor control sobre la nación mexicana (y por tanto poder supervisar este tipo de cuestiones) y que un contexto de crecimiento económico (el esperado tras el tratado) lo único que podía hacer era mejorar las condiciones de los trabajadores (Weintraub, 1993).

En lo que respecta a la cuestión medioambiental, el argumento es un poco similar: por un lado, se destaca que la escasa protección al medio ambiente tendría lugar también sin la firma del TLC, pero, una vez más, la clave está en proponer a los opositores acuerdos que garanticen una supervisión y un estricto control ambiental en la zona de frontera una vez entre en vigor el TLCAN(Weintraub, 1993).Además, también se da cuenta de las declaraciones del gobierno mexicano que sugieren que esta polémica "has been pounced on by certain U.S. lawmakers and otherswho seek the defeat of the North American Free Trade Agreement." (Noticia II, 1993)

A todos estos argumentos de tipo reactivo se suman los que en realidad son la tónica general, que son aquellos que defienden activamente la firma del tratado. En general, estos artículos coinciden en alabar al presidente Salinas de Gortari y reconocer que ha conducido a México hacia la senda del crecimiento, siendo capaz, por ejemplo, de reducir la inflación del $150 \%$ al $8,2 \%$ en los últimos años y de pasar de un déficit del 14\% del PIB a tener superávit (Medina Mora, 1993). Aunque se admite que quedan cuestiones que abordar, sobre todo a nivel microeconómico, se reconoce la velocidad de las reformas. El discurso que parece establecerse es que privatizaciones, comercio abierto y desregulación son siempre una vía efectiva para el crecimiento de un país, y que esos cambios son necesarios y deberían ser adoptados por otras potencias de la región (Singer, 1993). Es decir, que parece querer indicar que cuando dichos países adoptan la vía de imitación de la política norteamericana, sus resultados son siempre mejores.

Además de las cuestiones económicas, se habla también de una considerable mejoría en la "calidad de gobierno" desde finales de los ochenta y de una reducción de los niveles de corrupción. Estas afirmaciones, debemos matizar, aparecen en una carta al editor escrita por dos empresarios mexicanos molestos con el periódico por haber dado a entender que la corrupción seguía a la orden del día en México (Letter 1, 1993). Otro articulista invitado, también mexicano, va más allá y habla de "some local governments in Mexicowhere the entire political culture is being changed" (Chávez Barron, 1993). En el resto de artículos se describe más como una realidad futura que depende de la aprobación del Nafta.

Esto no quiere decir que el periódico rechace noticias o artículos que transmitan una visión negativa de México. Pero son menos numerosos. En todo el año apenas hemos encontrado un reportaje detallado en el que se hable del problema del narcotráfico, la violencia y el escaso peso de la ley como objeto central. El tráfico de drogas aparece 
también en las noticias relacionadas con la muerte del cardenal Juan Jesús Posadas el 24 de mayo de 1993 (entre otras en Bartley, 1993), aunque acaba diluyéndose y quedando como un episodio esporádico que además puede servir como toque de atención a la administración, pero como hecho atípico al fin y al cabo, más propio de zonas como Colombia. Aparece también de forma tangencial en alguna noticia sobre El Paso, pero como una cuestión menor, habitual en una frontera tan transitada.

Como vemos, durante el año 1993, el Wall Street Journal realizó una intensa campaña a favor de la aprobación del Tratado de Libre Comercio. Ante las numerosas dudas que el acuerdo generaba, el diario se esforzó por contrarrestar cada uno de los argumentos negativos, destacando las consecuencias positivas que tendría para los norteamericanos. Acompañando este proceso de defensa del tratado ante la opinión pública, el periódico fue construyendo una imagen de la nación vecina que generara confianza y erradicara los prejuicios que pudieran afectar negativamente a las relaciones comerciales, aunque siempre desde una posición de superioridad.En definitiva, el Journal de 1993 planteó una visión dual y variable, en la que México apenas se percibía como un ente propio, sino como vecino de Estados Unidos; aunque enfatizando la visión positiva y optimista.

\subsection{El agitado 1994}

Como hemos visto y a pesar de las contradicciones, en 1993 primaba un tono general de optimismo y esperanza ante lo que el futuro deparaba, considerando que la entrada en vigor del Tratado de Libre Comercio supondría un hito para la historia de Estados Unidos y México y el espaldarazo que la nación azteca necesitaba para terminar de impulsar su economía hacia el primer mundo y su cultura política hacia la modernidad.

Sin embargo, lo que hemos hallado para el año 1994 nos presenta una imagen completamente distinta a la predicha por el diario el año previo. La agitación política, sumada a los primeros signos decepcionantes de los efectos reales del Nafta en la economía de ambas naciones, provocaron un retroceso de la construcción imaginada de México hacia imágenes más tradicionales (el México corrupto, pobre, desigual...), a pesar de los intentos del Journal por evitarlo. De hecho, durante los primeros meses del año se observa una curiosa disociación entre el contenido de las noticias y el discurso construido en los artículos y editoriales. Mientras las primeras muestran muchos elementos que se describen como "desestabilizadores," los artículos tratan de llamar a los lectores a la calma y quitan importancia a los acontecimientos, intentando mostrarlos como algo esporádico y anormal en el estable México. Aunque este discurso empezará a fracturarse cuando la lista de acontecimientos "atípicos" y de inversores preocupados crezca. Lo más llamativo, sin embargo, es que en el aspecto económico este discurso ajeno a la realidad se mantiene hasta el final, hasta el estallido de la crisis de diciembre. Los signos negativos son menospreciados, mientras se destacan los datos económicos que apoyan la visión triunfalista del Nafta que buscaba el Wall Street Journal.

Durante el año las referencias a México pivotan casi siempre sobre los mismos temas: economía (primeros efectos del Nafta, inversiones...), alzamiento en Chiapas, drogas, secuestros, asesinatos políticos, incremento de la violencia y elecciones a la 
presidencia de la nación. Sobre ellos exponen el diario y sus colaboradores las ideas que a continuación vamos a detallar.

El acontecimiento que marcó el inicio del año fue el alzamiento del Ejército Zapatista de Liberación Nacional en Chiapas. Visto con mucha extrañeza y sin llegar a comprenderlo del todo, el diario fue narrando los primeros días de combate entre los zapatistas y las fuerzas de seguridad del estado. El mes de enero fue sin duda el mes del alzamiento en Chiapas en cuanto a volumen y repercusión mediática. La mayoría son noticias breves y con poco detalle. La rebelión se define como indian o peasant uprising y se explica que los rebeldes"were protesting abuses by authorities against Lacandon Indians in the region" (Noticia I, 1994).

Los artículos revelan más sobre los intereses del periódico. Pocos se centran en explicar el conflicto analizando sus causas. Estas sólo se analizan en algún un artículo:

The current government's focus on macroeconomic policy has often seemed out of touch with the concerns of the poor. (...) Petroleos Mexicanos, the Mexican oil giant, has found oil and natural gas and generates enormous profits -- almost all of which flow out of the state. (...) Violent disputes over land are legion between Indian campesinos, and the lighter-skinned ranchers, timbermen and coffee growers (Solís, 1994a)

En el resto parece darse por supuesto que el público asociará una rebelión en México a un contexto de pobreza y desigualdad, más tratándose de población indígena. El periódico prefiere poner el foco en las consecuencias que el alzamiento puede comportar para el PRI en las elecciones, ya que supone una "vergüenza" para el partido.

Autores como Jorge Castañeda consideraron que el alzamiento haría que México dejara de pensarse a sí misma como nación que avanza hacia el primer mundo (Castañeda en Solís, 1994a). Pero el Wall Street Journal combatió esta idea. La estrategia utilizada es disociar la realidad de Chiapas de la del resto del país. Para ello se muestra la imagen de un México en desarrollo (a través, sobre todo, de las noticias económicas) frente al atraso de Chiapas. La realidad chiapaneca suele describirse empleando comparaciones con Guatemala, estableciendo similitudes, tratando así de asociar en la imaginación de los norteamericanos la región conflictiva a la realidad centroamericana y no a la mexicana y norteamericana.

El análisis más complejo del diario lo firma Enrique Krauze. El escritor sitúa los orígenes remotos del conflicto en el fracaso del mestizaje (Krauze, 1994). La diferencia racial condenó a Chiapas, siguiendo la interpretación de Krauze, a una situación más desigual, despótica, en la que los caciques dictaban la norma.

Krauze acierta al afirmar que esta no es una "típica" rebelión campesina, sino una acción premeditada, con tácticas aprendidas de guerrillas centroamericanas y liderada por individuos que no tienen ascendencia indígena. Pero su análisis es devastador, muy duro. Denuncia una estricta jerarquía en la que los campesinos están sometidos a la voluntad de los líderes guerrilleros, quienes imbuidos de las ideas de la Teología de la Liberación y con el objetivo de implantar el socialismo, están dispuestos a sacrificar las vidas de estos 
indígenas en su lucha contra el gobierno. En su artículo reconoce el impacto psicológico del alzamiento y espera que sirva mejorar la situación política y económica en Chiapas.

Otro de los acontecimientos que captó la atención de los norteamericanos, y muy especialmente de los grandes empresarios, fue el secuestro en marzo del presidente de Banamex Alfredo Harp Helú, seguido del de uno de sus directores, Ángel Losada, en abril. El hecho sacó a la luz un problema hasta entonces apenas reflejado en los medios, por no tratarse de personajes relevantes, y transformó la imagen de México en la un país con mayor nivel de peligrosidad. El mayor daño a la imagen internacional de México vino al conocerse la relación entre los secuestros y las fuerzas de seguridad del Estado: "policemen or former policemen are so often involved in crimes that it is hard to trust the police forces to solve them" (Carroll, 1994a). Estas informaciones recuperaban esa visión del México corrupto a todos los niveles.

La incertidumbre durante las negociaciones con los secuestradores tuvo efectos muy negativos en la bolsa y desanimó a muchos hombres de negocios con planes de introducirse en México, a pesar de las llamadas a la calma del Journal, en el que se insistía en que los objetivos eran siempre mexicanos y que no parecía existir peligro para los extranjeros (Carroll, 1994b).

El mes de marzo fue particularmente aciago para la reputación internacional de México. Además del secuestro de Harp Helú, el miércoles 23 de marzo moría asesinado Luis Donaldo Colosio, candidato a la presidencia de la nación por el PRI. EI WSJ se apresuró a dar una imagen de estabilidad y calma, reflejando la tranquilidad de los mercados. EI periódico dedicó un editorial a subrayar la estabilidad del país, a arropar a los inversores y a insistir en el deseo de los mexicanos de avanzar hacia la modernidad, reconociéndoles sus méritos:

The secret to Mexico's success lies primarily with the Mexican people and their desire to become part of the global economy -- particularly the economy of the United States across the border (Editorial I, 1994).

Durante el mes de marzo los reporteros del WSJ se ciñeron a la versión oficial de que el responsable del asesinato había sido un lobo solitario. En algún momento se mencionan las teorías sí publicadas en medios mexicanos que barajaban como responsables tanto a la línea dura del PRI como a los partidos de la oposición o al EZLN. Sin embargo en el mes de abril las menciones a estas teorías, a las que se añaden los posibles lazos de los culpables con el narcotráfico, empiezan a ser más habituales. Observamos aquí la que a nuestro juicio es la primera fractura en el discurso de estabilidad y normalidad del Journal. Motivados quizá por la coincidencia con el segundo secuestro (el de Ángel Losada), que va sumando en la larga lista de "desgracias", los reporteros del WSJ comienzan a participar de un discurso más pesimista que va transformándose para generar en el lector la percepción de un México corrupto, violento e inseguro, con unas élites en el poder que se niegan a abandonarlo sin luchar.

Ante esto, el asesinato de Colosio e incluso de la revuelta de Chiapas se interpretan como ejemplos de resistencia a la modernidad, algo que por otro lado muchos autores ven como una constante en la historia de México. Rescatando las ideas de Samuel 
Huntington, autores como Héctor Aguilar Carmín, director de la revista Nexos, sugieren que...

...los cambios en el orden político existente derivan de las fuerzas de la modernización (...) la modernización interrumpe y desafía el ritmo tradicional de las sociedades, fuerza un cambio de hábitos, (...) rechaza la inercia y perturba el equilibrio de la sociedad (Aguilar, 1994).

Resulta interesante el argumento porque, desde la línea editorial del periódico, el objetivo es presentar a México como una nación moderna a toda costa, incluso empleando acontecimientos que en apariencia podrían sugerir un atraso, pero que se aprovechan en el discurso como ejemplos de esas resistencias a la modernidad y pasan así a convertirse en elementos necesarios para completar el proceso modernizador.

David Asman, editor de la columna The Americas, aprovecha también una entrevista a Octavio Paz para reforzar estos postulados sobre la modernización. Paz sugiere que "What happened in Chiapas was a sign of the incompleteness of the modernization of Mexico". La tesis sostenida por Paz es que "sometimes the evolution of society moves ahead not only of the government, but ahead of existing political institutions. In Mexico, as all over the world, there is a rejection of the established political class."Sin embargo, se muestra esperanzado respecto a la cuestión de la violencia: "I don't think violence will become an integral part of the final push, because no one wants violence." Termina afirmando que México "is condemned to modernize"(The Americas, 1994).

El siguiente acontecimiento importante, al que el WSJ dio prioridad desde enero, fueron las elecciones presidenciales del 21 de agosto. El diario evaluó las posibles implicaciones del alzamiento en Chiapas y del asesinato de Colosio, que fue sustituido por el candidato Ernesto Zedillo Ponce de León. Aunque el WSJ parecía decantarse por el candidato del PRI, puesto que garantizaba la estabilidad del sistema (siempre preferible para los mercados), ante la posibilidad de una derrota del partido en el gobierno el Journal fue mostrando a sus lectores las alternativas posibles, haciendo evidente su preferencia por el candidato del PAN, Diego Fernández de Cevallos, ya que éste continuaría con las reformas iniciadas por Salinas.

Las noticias sobre las elecciones vuelven a mostrarnos una imagen contradictoria de México en el WSJ. Por un lado se insiste en reconocer las reformas democratizadoras, que garantizarán las elecciones más limpias en la historia del PRI, ${ }^{4}$ concediendo el crédito de las mismas (al menos parcialmente) a la voluntad política de los mexicanos. Las elecciones representan la oportunidad ideal para presentar al país ante la opinión pública norteamericana como una nación democrática y pacífica, pero Estados Unidos no está convencido de que su socio pueda valerse por sí mismo. El Journal plantea alternativas a la

\footnotetext{
${ }^{4}$ Las anteriores elecciones generales, celebradas en el 88, estuvieron rodeadas de acusaciones de fraude. El PRI, en connivencia con el PAN, fue acusado de amañar las elecciones que habría ganado Cuauhtémoc Cárdenas. Para algunos autores como Armando BARTRA el fraude está fuera de toda duda (Bartraen Chávez, 2008: 266). En el caso del WSJ las noticias en 1993 hablaban de rumores u opiniones muy extendidas pero no confirmadas. Sin embargo, en las noticias de 1994 cercanas a las elecciones sí llega a afirmarse que existió fraude (Solís, 1994b).
} 
intervención directa, dada la "obsesión por preservar la soberanía" (Baer, 1994) que tienen los mexicanos (cuestión que el diario siempre menciona con desprecio). La opción preferente consistió finalmente en financiar a ONGs para ejercer de observadoras en las elecciones. La medida era delicada, pues en muchos casos estas organizaciones habían surgido de la oposición al PRI y eran cercanas al PRD, con lo que su neutralidad estaba en entredicho.

El WSJ destaca también el papel fundamental jugado por Estados Unidos en la democratización del país más allá de las ayudas a las organizaciones observadoras. El periódico hace referencia al papel jugado por el Nafta. El Journal bebe de las teorías políticas que mencionábamos en el apartado previo que relacionan democracia y desarrollo económico y atribuye al pacto la capacidad de influir en la política interior mexicana, por la propia dinámica de la economía global y por la voluntad de México de agradar a USA.

Esta idea es constante a lo largo de los artículos que describen los logros de estas elecciones. Aunque se mencionen dinámicas internas mexicanas, el impulso definitivo, la palanca de cambio, siempre viene del exterior: "with foreign investors gaining influence and insisting on a fair vote, the elections are expected to be the cleanest in Mexican history" (Carroll y Solís, 1994).

Las elecciones dieron una victoria clara a Zedillo, mucho más holgada de lo que se esperaba. Desde el editorial del WSJ se interpretó como un apoyo al ala reformista del PRI, en definitiva, un apoyo a las políticas librecambistas. Por eso se invita de forma explícita a los norteamericanos a valorar los avances de su vecino y a erradicar estereotipos:

There has been a long-standing notion that Mexico is a cauldron of leftist, anti-gringo resentment. The broad center of American society should take heart from the Mexican elections. Its ideas of free enterprise and democracy produced a strong resonance in what is still a poor and sometimes cynical electorate. If this can happen in Mexico, why not in every developing nation?(Editorial II, 1994)

Pasada la resaca de las elecciones 1994 todavía reservaba sorpresas a los mexicanos y a los estadounidenses. El 28 de septiembre era asesinado José Francisco Ruiz Massieu, Secretario General del Comité Ejecutivo Nacional del PRI. La noticia fue recibida como un mazado. La imagen de México volvía a ser la de la violencia política. A diferencia del asesinato de Colosio, en este caso el WSJ admite desde el principio las distintas teorías sobre las causas, siendo la tesis de un acuerdo entre el narco y la guardia vieja del PRI la que coge más fuerza en las primeras semanas (Solís, 1994c).

Si el asesinato de Colosio podía atribuirse a una excepción, el de Ruiz Massieu apuntala la percepción de una violencia asentada, y hace que los reporteros recuerden otras muertes que ya habían quedado olvidadas, como la del cardenal Juan Jesús Posadas o la del jefe de policía de Tijuana, cuya muerte se relacionó con el caso Colosio, pero a la que el WSJ inicialmente apenas prestó atención. La suma de todos estos episodios revela un panorama menos halagüeño de lo que al WSJ le gustaría. 
La situación empeora en noviembre cuando se acusa al PRI de entorpecer la investigación, aunque el desarrollo de la historia durante 1995, con la detención de Raúl Salinas de Gortari, hermano del expresidente, dejó a los inversores en shock.

El asesinato de Ruiz Massieu nos permite hablar de otro de los elementos clave en la cobertura del Journal: la referencia al narcotráfico. Si para 1993 no encontrábamos apenas referencias a la cuestión del tráfico de drogas, en 1994 observamos un cambio considerable. Ya en enero hay alguna referencia, y en marzo tras el asesinato de Colosio alguna más; pero el verdadero cambio se observa durante los cuatro últimos meses del año. Lo que preocupa a los lectores y a los mercados, cada vez más volátiles, no es sólo la presencia de cárteles operando en México, sino los estrechos lazos con la administración a todos los niveles que las noticias van revelando. Se retrata como un problema relativamente reciente que todavía no es irresoluble, pero que supone un peligro grave para la nación ( $y$, con ella, para los inversores, en los que el Journal siempre piensa). Se reflejan los miedos de los mexicanos, a los que les preocupa la "colombianización" del país y que México se convierta en una "narcodemocracia" (Carroll, 1994b).

Respecto a las noticias y artículos de temática económica, como comentábamos al inicio, hay un esfuerzo evidente por enfatizar lo positivo frente a los indicios de una recesión o la bajada preocupante del valor del peso.

En conjunto, el WSJ suele definir el Nafta como un éxito. Sin embargo desde los primeros meses del año encontramos noticias (que no artículos) que relativizan esa postura. En febrero, por ejemplo, se reconoce por primera vez que existe frustración ante las perspectivas del libre comercio entre los granjeros y campesinos de varios estados (Solís, 1994d), también entre los empresarios, que reconocen que ahora la economía mexicana es más competitiva, pero a expensas de muchas compañías que han quedado en el camino sin dárseles tiempo para adaptarse y que se sienten abandonadas por el gobierno (Fritsch, 1994). Son opiniones que en 1993 el diario evitó convenientemente, mostrando sólo los apoyos al TLC. Aparecen también negociaciones frustradas o acuerdos que llegan a su fin, aunque en los artículos se justifica por la situación política de incertidumbre y se espera que la situación cambie.

Lo que no cambia es la idea de superioridad estadounidense, que siempre se percibe a sí mismo como un socio desinteresado que ayuda a México, considerablemente menos avanzado que él. En un artículo referido a la posible entrada de distintos bancos norteamericanos en México (prevista para 1995), el artículo valora lo útil que esto podría ser para ayudar a modernizar México, sin mencionar en ningún momento los beneficios de los bancos (Knecht, 1994).La ayuda siempre se concibe como unidireccional, hay muy pocos casos en los que se refleje una voluntad de aprender de México.Porque pervive en el imaginario la idea de toda una región (América Latina) determinada por los males endémicos de la "pobreza," "el control de las oligarquías," "la debilidad de las instituciones" $y$ "las divisiones étnicas." Y abandonada al despilfarro económico "since the days of the Spanish viceroys" (Moffett, 1994).

Desde mediados de año detectamos también noticias que muestran una caída en el consumo. Mientras en 1992 el consumo privado creció un 5,9\%, en 1993 se contrajo un $0,1 \%$ (Firtsch, 1994). Aunque no es un dato muy negativo, refleja un cambio de tendencia visible al que el diario prestó poca atención. El discurso seguía siendo de éxito rotundo del 
Nafta.

En estos meses una de las valoraciones más positivas por parte del periódico, además de Salinas de Gortari, la recibe Pedro Aspe, su Secretario de Hacienda. Se destacan los cambios estructurales y el alcance de sus reformas pero, por encima de todo, se da a conocer al público estadounidense su paso por la Universidad de Harvard junto con Foxley (Chile) y Cavallo (Argentina). Esta confluencia de ministros en países clave de América Latina educados en Estados Unidos es para el Journal la mejor prueba del buen camino que sigue el continente. Considera el diario que ahora que los líderes económicos se forman en Estados Unidos por fin se puede hablar un mismo lenguaje de mercado.

Pero el balance clave del primer año del TLC llegó en octubre. A final de mes el Journal publicó un reportaje especial con numerosos artículos que valoraban el tratado desde distintos puntos de vista. Los artículos más teóricos siguen manteniendo la tesis de un balance positivo, pero aquellos que se aproximan a lo micro muestran numerosas dificultades. Especialmente llamativos son los dos artículos que hablan de las diferencias entre hacer negocios en México y Estados Unidos, uno desde la perspectiva de cada país. Mientras el artículo de los mexicanos introduciéndose en el mercado estadounidense en una única historia con un toque humano, en la que los problemas encontrados en USA se reducen a detalles menores esperables en cualquier empresa internacional (Carroll, 1994c); el artículo que refleja las experiencias de emprendedores norteamericanos en México es una continua descripción de los graves problemas que presenta el país (Carroll, 1994d). Muchas de las críticas que aparecen en el artículo (exceso de burocracia, falta de preparación, atraso tecnológico, infraestructuras deficientes, un sistema judicial atrofiado...) no los veíamos en el periódico desde 1993, lo que supone un retroceso considerable. Los estadounidenses que invierten en México desprecian las costumbres del país y llegan con una idea errónea, con la creencia de que México es una mezcla entre un territorio virgen y el salvaje oeste, un lugar excitante en el que se puede arrasar con todo sin consecuencias. Sin embargo entre los mexicanos el mito de EE.UU. como tierra de oportunidades pervive (Carroll, 1994c).

En definitiva, el discurso del WSJ se empeñó en presentar el TLC como un éxito rotundo, aunque si prestamos atención a todas las noticias vemos que la tesis del diario es muy matizable ya que, aunque a gran escala el comercio durante los primeros meses creció de forma considerable, fueron apareciendo pequeños problemas e indicadores que daban pistas sobre lo que ocurriría en diciembre.

El mes de diciembre de 1994, con la crisis de la devaluación del peso, y los primeros meses del 95, con la investigación del asesinato de Ruiz Massieu que comentábamos anteriormente salpicando al expresidente Salinas de Gortari, otrora venerado como modernizador de México, acabaron con los intentos del Wall StreetJournal por mostrar un nuevo y desarrollado México, recuperando las visiones más tradicionales del fracaso económico, el atraso y la corrupción.

\subsection{El TLC en la frontera: California, Texas y el debate de la inmigración (1993-94)}

Si en alguna región en particular se debatió la aprobación del TLC con intensidad esa fue el suroeste de Estados Unidos. Los estados que compartían frontera con México tenían 
mucho que ganar o perder con la firma del Tratado. Las posturas expresadas reproducen el debate a nivel nacional. Sin embargo se detecta en el Wall Street Journal una particularidad muy importante. En la región fronteriza los prejuicios que influyen en las diversas opiniones sobre el Tratado están más determinados por la imagen que se tiene de los inmigrantes mexicanos residiendo en suelo norteamericano que por la visión que se tiene del propio México. De este modo, en los estados fronterizos el debate sobre el tratado estuvo indisolublemente ligado al debate de la inmigración. Además, los lazos con comunidades al otro lado de la frontera son más estrechos, y se percibe en el debate una preocupación mayor por la influencia del tratado en el desarrollo a nivel local.

De todos los estados fronterizos, el WSJ se centra siempre en dos: Texas y California, que representan dos modelos opuestos, dos formas distintas de afrontar la emigración hispana procedente fundamentalmente de México. Explicaba el Wall Street Journal en 1993 que California, estado más progresista, había abogado en las últimas décadas por un modelo de atención al migrante más asistencialista. En Texas, por el contrario, los migrantes sabían que no iban a obtener todo tipo de asistencia con lo que, argumentan los editores del WSJ, Ilegaban sabiendo que debían trabajar.

Esta diferencia hizo que con el paso de los años California no lidiara bien con el flujo de migrantes, lo que en los años 90 había terminado alterando y empeorando la visión que los residentes tenían sobre los inmigrantes. En Texas, sin embargo, eran generalmente vistos "como trabajadores, no como meros receptores de prestaciones sociales" (Editorial III, 1993). Para el periódico, la visión sobre los inmigrantes condicionaba totalmente la imagen que el ciudadano medio americano se construía sobre el país vecino, ya que extrapolan su realidad más cercana al concepto más difuso para ellos de nación mexicana.

El diario argumentaba que allí donde el sistema funciona mejor (expresión que, para un periódico conservador como el Journal, pasaba por seguir una política como la texana) se demuestra también que la convivencia entre las dos comunidades puede darse sin problemas, por lo que a nivel internacional sucedería lo mismo. Si el Nafta se aprobaba, ambos países funcionarían mejor si se respetaban las reglas establecidas en el marco económico fijado.

Y lo cierto es que, durante el año 94, las hipótesis del Journal parecen confirmarse. Las noticias referidas a Texas son mucho más habituales e impera en ellas un tono triunfalista. Mientras tanto, las menciones a California son más escasas y reflejan una situación económica catastrófica que no ha logrado beneficiarse de la firma del Tratado, repercutiendo negativamente en la imagen de los inmigrantes, a los que se culpa de la crisis estatal.

El diario describe en enero y febrerode 1994 las primeras impresiones de la puesta en marcha del pacto, centrándose en los aspectos positivos. Esto genera además una valoración positiva de México y de los empresarios mexicanos. También a los inmigrantes se les percibe como parte integrante de la comunidad, por lo que desde el gobierno estatal se busca ofrecer ayudas a los inmigrantes empobrecidos que residen en la frontera, aunque no mediante subsidios como el modelo californiano, sino favoreciendo la inversión de los grandes fondos de pensiones en viviendas de bajo coste que los inmigrantes pudieran adquirir (Parker, 1994). 
Aunque no todos los artículos escritos desde Texas son tan positivos. En algunos casos reflejan la frustración y el desencanto con el Tratado, del que se esperaba un mayor efecto a corto plazo sobre el comercio. Este hype excesivo lleva al desencanto y a buscar culpables, que siempre se encuentran al otro lado de la frontera. El diario reproduce las quejas de distribuidores que observan un desprecio de los mexicanos por la ley: "The problem is, they ignore their own laws in their own country," he says. "The question is whether they'll voluntarily follow U.S. laws"(Allen, 1994a).También se narran las tensiones en aquellos puntos de la frontera donde los controles migratorios se incrementan, vistos como una ofensa por parte de los mexicanos. Estos, además, coinciden con las áreas de menor crecimiento económico (El Paso - Ciudad Juárez).Aquellas en las que la economía está creciendo (ejemplo paradigmático es la pareja Laredo - Nuevo Laredo) no evidencian tensiones en la frontera (Allen, 1994b), demostrando una vez más la fuerte conexión para el diario entre el Tratado de Libre Comercio y la percepción de la población inmigrante. Se hace evidente también como ambas economías van integrándose y empezando a conocerse mejor, lo que lleva a unas descripciones del área de frontera más complejas que las vistas para el año anterior.

En California la atmósfera es bien distinta. La relación discursiva que se establece entre crisis e inmigración empieza a calar a mediados de año entre la población.

The California governor is leading, or at least riding, an anti-immigration bandwagon in this economically strapped state. He rarely misses an opportunity to blame California's woes on too much immigration and is supporting a draconian initiative this November that would strip illegal aliens of health and welfare benefits and deny schooling to their children.

It's working. The incumbent Republican, trailing badly a year ago, now leads his Democratic challenger, (...) even though most voters still don't think he's been a good governor (Hunt, 1994).

La iniciativa a la que hace referencia la cita, conocida como Proposition 187, que negaba incluso el derecho a los hijos de los inmigrantes a asistir a la escuela, reabrió el debate sobre la inmigracióna nivel nacional, generando tensos enfrentamientos entre detractores y defensores de la iniciativa. Y es que la cuestión migratoria afecta a la definición misma de Estados Unidos, asentada en el imaginario colectivo como una nación de inmigrantes construida a sí misma("Californians don't understand what the United States stands for"; Rose, 1994), pero construida a la vez con un prototipo de ciudadano en mente (WASP) en el que el inmigrante mexicano no encajaba porque no hacía esfuerzos por asimilar la cultura mayoritaria.

La cuestión de la identidad se mezcla también con la realidad económica más mundana. La iniciativa generó tensión con el gobierno mexicano, aunque el WSJ aporta pocos datos sobre la reacción de la administración saliente de Salinas. De lo que sí se hace eco el periódico es de la opinión contraria de los texanos a la medida, quienes sí ven a los inmigrantes como parte dinámica de su economía:

Both legal and illegal immigrants have contributed significantly to the Texas 
economy in terms of providing a lot of manpower, in filling jobs that a lot of U.S. citizens wouldn't take (Texas Journal, 1994).

Esa visión positiva de los mexicanos y de México se mantuvo en Texas incluso tras el estallido de la crisis mexicana en diciembre. De hecho, percibimos que frente a las tensiones a nivel nacional (provocadas por el temor y por el rechazo del Congreso a enviar ayuda a México) la sección Texas Journal opta por hacer más explícitas las buenas relaciones entre la región y el vecino del sur, especialmente con la región industrial del norte de México. Se destaca el contraste entre el norte de México y el resto del país, haciendo hincapié tanto en el mayor desarrollo económico como en la mayor independencia de sus políticos, quienes desconfían de las élites asentadas en México DF (Allen, 1995). Desde el WSJ se propone integrar todavía más ambas economías, pues el TLC ha permitido ver las similitudes económicas (especialmente entre Texas y el estado de Nuevo León) y descubrir que ambos "comparten una única cultura empresarial” (Ibíd.).

Como vemos, un análisis más alejado de los grandes discursos a nivel nacional nos ofrece una perspectiva rica y matiza la visión general, mostrando un balance del TLC tras su primer año de vida más positivo, al menos en el terreno de la percepción de los estadounidenses.

\section{CONCLUSIONES}

Creo que podemos afirmar a la luz de la investigación que hubo un intento deliberado y muy consciente del WSJ por transformar la imagen que los estadounidenses tenían de México. Éste no obedeció a razones humanitarias o de reparación histórica, en absoluto, sino que interesaba para facilitar la transición al área de libre comercio, política defendida desde la línea editorial del periódico. Partíamos al inicio de las ideas de Greg Anderson sobre el peso de los prejuicios y estereotipos en la toma de decisiones. Efectivamente, hemos observado que el Wall Street Journal trató de moldear el concepto que los norteamericanos tenían sobre México para servir a intereses comerciales: lograr inclinar la balanza en la votación parlamentaria del Nafta y animar a los empresarios e inversores a lanzarse a la conquista del mercado mexicano sin temer repercusiones negativas en casa.

Para ello el periódico presentó una imagen de un México nuevo, en el que todo aquello que tradicionalmente se había asociado a la nación vecina (corrupción, atraso, tercermundismo, proteccionismo...), aun existiendo todavía, estaba siendo erradicado para entrar en el primer mundo siguiendo el ejemplo de Estados Unidos (que los lectores asociaban a democracia, justicia, libertad, economía de mercado, éxito internacional, etc.). Un México para el que el TLC sólo iba a traer cosas positivas, incluyendo avances democráticos, en ese lazo que se establece desde el diario entre crecimiento económico y afianzamiento de la democracia.

Esto no quiere decir que la imagen de México durante el año 1993 fuera monolítica. Con esta visión de la modernidad mexicana convive la del atraso, y el diario empleó una u otra según su conveniencia, mostrando aquello que atrajera o calmara los temores de sus lectores según las circunstancias. 
Pero, a grandes rasgos, primaba la visión modernizadora. El gran artífice del cambio fue el presidente Carlos Salinas de Gortari, en quien el diario centra todas las alabanzas. Otro de los elementos más destacados por el WSJ como palanca de cambio es precisamente el interés de Estados Unidos por el país del sur y la presión ejercida por los inversores extranjeros. Por encima del papel del EZLN, la oposición (tanto del PAN como del PRD), o la fuerza de la sociedad civil, el periódico presenta a Estados Unidos (tanto al Ejecutivo como a los empresarios) como los impulsores definitivos de la transformación del país.

Sin embargo, consideramos que la campaña del WSJ sobre México fracasó en gran medida, ya que los acontecimientos de 1994 devolvían un paisaje tan lejano a lo que USA entendía como una nación exitosa, libre y democrática, que fue imposible para el periódico convencer de que aquello que los lectores leían era fruto de la casualidad, algo pasajero, y no parte intrínseca del carácter y la historia mexicana (como sí habían conseguido dar a entender, a nuestro juicio, en 1993). Los logros del año anterior quedaron eclipsados por los acontecimientos de 1994.

Y eso que el diario lo intentó hasta el final y por todos los medios. Quizá llama especialmente la atención la postura en materia económica, por ser el ámbito de especialización del diario. El WSJ defendió la firma del tratado a toda costa, pasando por alto incluso las señales que indicaban que la economía mexicana no estaba respondiendo como se esperaba ya desde finales de 1993, unos meses antes de que entrara en vigor el tratado, e insistiendo en el milagro económico que había tenido lugar en México.

Dicho esto, sí creo que hubo una modificación parcial, y sobre todo una ampliación, en la idea que los norteamericanos tenían de México, mostrando una mayor flexibilidad de las percepciones de lo que pensamos a priori. En cuando a la modificación, aunque es pequeña, sí consideramos que el WSJ reconoce ciertas mejoras democráticas y un avance en la transformación del sistema político. Desgraciadamente la acumulación de acontecimientos "desestabilizadores" durante el año 94 fue llamativa, destruyendo parte del trabajo hecho por el periódico durante el año anterior. Por tanto teniendo esto cuenta podríamos hablar de fracaso pero con paliativos.

En cuanto a la segunda parte, la ampliación de la imagen que los estadounidenses tenían de México, creemos haber detectado un cambio importante, y es el elemento del narcotráfico, la violencia y la inseguridad. Empleamos el término ampliación y no transformación porque no es que previamente existiera una concepción opuesta que se vio alterada, sino que son elementos de nuevo cuño que se habían ido gestando en los años ochenta pero que, a juicio de nuestra investigación, salieron realmente a la luz de la opinión pública estadounidense en 1994. Como hemos señalado en el análisis del WSJ, las referencias al narcotráfico son prácticamente inexistentes durante 1993. Apenas hay un artículo que aborde la cuestión de las drogas como tema central y un pequeño puñado más que lo mencionen de forma tangencial, pero siempre como un problema menor habitual en cualquier frontera o como consecuencia del desplazamiento de las rutas de los narcotraficantes colombianos. En 1993, hablar de droga remite en el imaginario norteamericano a los cárteles colombianos. México parece señalarse como lugar de paso, pero no se asocia todavía tan directamente al narcotráfico. No quiere decir que el 
problema no existiera, porque había empezado a desarrollarse en la década anterior, sino que todavía no había llegado a configurarse como estereotipo.

1994 supuso un cambio fundamental a este respecto. Como hemos visto, las referencias a los cárteles mexicanos y sus lazos con las instituciones corruptas empiezan a convertirse en una noticia habitual. Es especialmente significativa la especulación generada tras los asesinatos de Luis Donaldo Colosio y José Francisco Ruiz Massieu, relacionadas con los sectores no reformistas del PRI. Sugerimos pues que el estereotipo de México como una nación invadida por el narcotráfico se gestó en 1994. A ello se suma el salto a los titulares del secuestro de Harp Helú. Otro fenómeno, el de los secuestros, que llevaba unos años produciéndose pero que no alcanzó relevancia mediática hasta este momento.

Sobre si el WSJ logró los objetivos económicos que se proponía también podemos extraer algunas conclusiones. Como sabemos, todo ese esfuerzo por redefinir México iba encaminado a aprobar y apoyar el TLC. Si basamos nuestra evaluación únicamente en la votación en el Congreso, deberíamos afirmar que la campaña de agenda-setting funcionó. No obstante, la repetición en artículos y noticias de los conceptos básicos del acuerdo una y otra vez durante todo el año da a entender que no se prestaba tanta atención al TLCAN como el Journal deseaba. Observamos durante todo el año cómo la publicación trató de convencer a aquellos sectores que podían influir en los legisladores, empezando por el propio Clinton, al que vemos en las páginas del Journal siguiendo un rumbo errático, preso de los compromisos electorales y sin un criterio propio hasta bien entrado el año.

Aun así el acuerdo se aprobó. El diario, desprovisto ya de la necesidad de captar votos, prestó menos atención a México que al año anterior $y$, como hemos comentado arriba, no fue capaz de mantener la representación idealizada del país. Juzgar el éxito o el fracaso del Nafta estudiando sólo sus primeros meses de existencia es imposible, no pretendemos tanto. Aunque, desde luego, el balance de ese primer año no es muy positivo. De hecho, nos aventuramos a plantear que el cambio en la imagen de México motivado por los acontecimientos de 1994/95 influyó en la percepción del propio tratado y pudo pesar en la oposición a la ampliación inicialmente prevista a Chile, primero, y a otros países latinoamericanos después.

En todo esto percibimos la maleabilidad de ciertas percepciones, que se construyen sirviendo a un fin pero cuando ya no sirven vuelven a su forma tradicional, la que constituye el núcleo que no ha logrado alterarse. O quizá sería más acertado hablar de un "banco de imágenes" por expresarlo gráficamente, en el que Estados Unidos concibe diversos Méxicos y escoge el que más conviene en cada momento. Porque esa es otra constante extraída del análisis: el diario sólo se preocupa por lo que conviene a Estados Unidos.

En el caso del TLC, se asume como natural la voluntad de México por pertenecer al área libre comercio y se parte de la base de que, en todos los casos, la firma siempre beneficia a México, sin valorar las consecuencias negativas del Nafta para ellos.

Otra de las conclusiones obtenidas del estudio del Journal es el contraste de opiniones en la frontera, con unos resultados distintos de lo esperado. Comparando las noticias y opiniones escritas desde o sobre Texas y California, nos encontramos con una visión muy positiva (en términos generales) de México y de los inmigrantes mexicanos en 
Texas frente al rechazo y las tensiones de California. La divergencia de opiniones se debió fundamentalmente a la desigual situación económica de ambos estados. Mientras Texas disfrutaba de unos niveles de crecimiento estables, California atravesaba su crisis más profunda desde la Gran Depresión. Como consecuencia, observamos un recrudecimiento de las relaciones con la comunidad hispana, cuyos derechos en territorio norteamericano fueron cuestionados hasta el punto de presentar una proposición de ley que privaba a los indocumentados de atención sanitaria o educación, con un apoyo masivo por parte de la población californiana. Nos resulta llamativo porque contrasta con la visión tópica de la Texas más conservadora frente a una California más progresista.

De toda la nación mexicana, la región de la cual se ofrece una visión más favorable es el norte de México. Si bien consideramos que no puede hablarse de la construcción de una identidad regional transnacional, porque se marcan mucho los contrastes entre ambos países, sí podemos hablar de una mayor convergencia de caracteres en la zona de frontera. El Wall Street Journal se esfuerza por diferenciar el norte industrializado y más desarrollado del resto del país, destacando la existencia de una cultura empresarial más próxima a la texana que a la chilanga.

Así, se establece lo bueno de México por asimilación a Estados Unidos, mientras que lo más alejado de Estados Unidos (literal y figuradamente) representa lo negativo. El sur, con mención especial a Chiapas, es todo aquello que se desea que México no sea (pobre, atrasado, rural...) y se procura desvincularlo de la imagen del país asociándolo a Centroamérica. Se van configurando así tres Méxicos, en una gradación de lo más a lo menos deseable, de lo más a lo menos asimilado con el vecino del norte.

$Y$ es que, en el fondo, para los lectores del Journal la salvación de México pasaba por Estados Unidos. Por asimilar el modelo económico que conduce al desarrollo y la democracia (he aquí otra idea fundamental del WSJ, que es el desarrollo el que trae la democracia y no a la inversa). Aquí, Estados Unidos refleja su propia concepción como país, esa idea de superioridad que bebe de la teoría del destino manifiesto y que les hace verse a sí mismos como salvadores del mundo. Una salvación supeditada a la obediencia del salvado.

\section{BIBLIOGRAFÍA:}

Anderson, Greg. 2008. "Institutions of NAFTA". Norteamérica. Año 3, no 2, 11-41.

Arrese, Ángel. 2002.Prensa económica: De la Lloyd's list al wsj.com. Pamplona: Ediciones Universidad de Navarra, S.A.

Bartra, Armando. 2008. "México. Añoranzas y utopías: La izquierda en el tercer milenio", en Chávez, Daniel; César Rodríguez Garavito y Patrick Barrett (eds.).La nueva izquierda en América Latina.Madrid: Catarata.

Hobsbawm, Eric J. 1998. Sobre la historia.Barcelona: Crítica.

\section{Documentos primarios:}

- Firmados: 
Aguilar Carmin, Héctor. 1994. "The Americas: The Price Mexico Must Pay for Modernization".The Wall Street Journal. 29/04/1994.

Allen, Michael.1994a. "TEXAS JOURNAL - Focus on Nafta: It Had to Happen: A Tale of Nafta Disenchantment". The Wall Street Journal. 02/03/1994.

-- 1994b. "TEXAS JOURNAL - El Paso Asks: Will Nafta Be Much Help, After All?".The Wall Street Journal. 18/05/1994.

-- 1995. "TEXAS JOURNAL -- Texas and a Big Neighbor Move Toward Closer Ties".The Wall Street Journal. 01/02/1995.

Baer, M. Delal. 1994. "The Americas: Observing the Mexican Election Observers".The Wall Street Journal. 03/06/1994.

Bartley, Robert L. 1993. "Drug-War Death: Cardinal's Blood To Purify Mexico?". The Wall Street Journal. 09/06/1993.

Breger, Marshall. 1993. "The Americas: Nafta Critics Have It All Wrong on Mexican Labor Law". The Wall Street Journal. 15/01/1993.

Carrington, Tim. 1993. "The Outlook: North American Pact May Go Beyond Trade". The Wall Street Journal. 11/01/1993.

Carroll, Paul B. 1994a. "Same Group May Have Kidnapped Mexican Retail Executive and Banker".The Wall Street Journal. 27/04/1994.

-- 1994b. "Mexicans Discover Kidnapping Is a Growing Part of Business Risk". The Wall Street Journal. 18/03/1994.

-- 1994b. “Officials Fingered in Mexico Assassination --- Statement by Accomplice Points to Key Politicians In Party Leader's Death". The Wall Street Journal. 13/10/1994.

-- 1994c. "Nafta (A Special Report): Following the Money --- The Brass Ring: For Mexican companies, the U.S. market Represents a Shining opportunity -- If they can figure out how to crack it". The Wall Street Journal. 28/10/1994.

-- 1994d. "Nafta (A Special Report): Following the Money --- A Different World: Yes, the potential is mind-boggling; But U.S. companies are often unprepared For just how different Mexico is".The Wall Street Journal. 28/10/1994.

Carroll, Paul B. y Solís, Dianne. 1993. "Power and Its Problems Taming Gov. Barrio, A Longtime Opponent of Mexico 's Government". The Wall Street Journal. 07/09/1993.

-- 1994. "Separate Ways: Paths of Two Friends Reflect the Conflicts That Split Mexicans --On Verge of Elections, One Seeks Stability, the Other A Stronger Democracy --- Crucial Bond Is Tolerance". The Wall Street Journal. 19/08/1994.

Chávez Barron, Héctor. 1993. "The Americas: Much More to Mexican Politics Than Who's at the Top". The Wall Street Journal. 3/12/1993.

Edmonds, Duncan. 1993. "The Americas: Canada's Critical Malaise of the Spirit". The Wall Street Journal. 05/02/1993.

Ehrbar, Al. 1993. "Trading Up: Many U.S. Companies Expect Strong Exports Despite Talk of Slump --- They Say Weakness in Japan, Germany Will Be Offset By Latin American Gains --- Surprises in Consumer Goods". The Wall Street Journal. 18/01/1993.

Fritsch, Peter. 1994. "Economists Say Mexico Needs New Strategy - With Frustration Rampant, Some Recommend Cuts in Rates, Cheaper Peso". The Wall Street Journal. 16/05/1994. 
Hunt, Albert R. 1994. "Politics \& People: Demagoging the Immigration Issue", The Wall Street Journal. 07/07/1994.

Knecht, G. Bruce. 1994."Major U.S. Banks Plan Units in Mexico --- Move Could Help Modernize Financial Infrastructure".The Wall Street Journal. 31/05/1994.

Krauze, Enrique. 1994. "The Americas: New Zapatistas Sully Memory of Their Namesake".The Wall Street Journal. 21/01/1994.

Medina Mora, Eduardo. 1993. "The Americas: Mexico's Economy Needs One Last Shot In the Arm". The Wall Street Journal. 8/10/1993.

Moffett, Matt. 1994. "Seeds of Reform: Key Finance Ministers In Latin America Are Old Harvard-MIT Pals --- Change in Mexico, Argentina And Chile Traces Back To Student Days in 1970s --- Spreading the Market Gospel". The Wall Street Journal. 1/08/1994.

Parker, Tara. 1994. "TEXAS JOURNAL - Fund Sees Promise in Bleak Borderland". The Wall Street Journal. 09/02/1994.

Robbins,Carla Anne. 1993. "Nafta's Opponents Turning Spotlight On Mexico's Record in Human Rights".The Wall Street Journal. 4/10/1993.

Rose, Frederick. 1994. "Anti-Immigrant Plan In California Revives Economic Questions --Newest Illegals May Not Fit In State With Future Need For More Skilled Workers". The Wall Street Journal. 04/11/1994.

Rowen, Henry S. 1993. "Beyond the Cold War - Foreign Policy in the $21^{\text {st }}$ Century: Cheer Up, Troubled World".The Wall Street Journal. 31/08/1993.

Singer, Carlos. 1993. "The Americas: Chile: The Stalled Latin Tiger". The Wall Street Journal. $1 / 10 / 1993$.

Solís, Dianna. 1993a. "When Clinton Meets Mexico's Salinas, Agendas on Free Trade Might Not Mesh".The Wall Street Journal. 06/01/1993.

-- 1993b. "Life by the Road: Twin Border Cities Bear Brunt of Trade --- Busy U.S.- Mexico Truck Route Has Laredo Area Concerned About Affects of Trade Pact". The Wall Street Journal. 29/03/1993.

-- 1994a. "Mexico Uprising May Aid Rival For Presidency".The Wall Street Journal. 03/01/1994.

-- 1994b. "Mexico Tries to Ensure Fraud-Free Vote As Credibility Becomes Election Issue". The Wall Street Journal. 20/07/1994.

-- 1994c. "Mexico Roiled by Conspiracy Theories, Many Drug-related, After Latest Killing". The Wall Street Journal. 30/09/1994.

-- 1994d. "Mexico Faces Slow Growth Of Economy --- In Fourth Period, an Increase Of Just 0.2\% Fell Below Expectation for 0.5\% Rise". The Wall Street Journal. 22/02/1994.

Weiner, Benjamin. 1993. "The Crime of Selective Morality". The Wall Street Journal. 11/02/1993.

Weintraub,Sidney. 1993. "Nafta Through the Looking Glass". The Wall Street Journal. 6/10/1993.

Wright, Jim. 1993. "Labor Take Note: Nafta Means Jobs For U.S. Workers". The Wall Street Journal. 7/10/1993.

- Sin firma recogida: 
Carta. 1993. "Letters to the Editor: A Land of Promise For Business Ventures", The Wall Street Journal, Nueva York, News Corporation, 3/12/1993.

Editorial I. 1993. "REVIEW \& OUTLOOK (Editorial): Opportunity in London". The Wall Street Journal. 26/02/1993.

Editorial II. 1993. "REVIEW \& OUTLOOK (Editorial): Nafta in the Balance". The Wall Street Journal. 04/03/1993.

Editorial III. 1993. "REVIEW \& OUTLOOK (Editorial): The New Neighborhood".The Wall Street Journal. 12/10/1993.

Editorial I. 1994. "REVIEW \& OUTLOOK (Editorial): Mexico 's Tough Test". The Wall Street Journal. 25/03/1994.

Editorial II. 1994."Review \& Outlook (Editorial) - Hope in Mexico". The Wall Street Journal. 24/08/1994.

Noticia I. 1993. “Clinton Faces Labor Opponents of Nafta, Promises Pact Won't Harm Jobs in U.S.", The Wall Street Journal. 5/10/1993.

Noticia II. 1993. "SCEcorp Drops Mexican Electric Plant Under Political, Environmental Pressure". The Wall Street Journal. 12/10/1993.

Noticia I. 1994. “What's News -- World-Wide”. The Wall Street Journal. 03/01/1994.

Texas Journal. 1994. "TEXAS JOURNAL -- What Now? Free Advice for the Elected --Promote Exports, Fix Schools, Build Bridges -- And No New Taxes". The Wall Street Journal. 09/11/1994.

The Americas. 1994. "The Americas: A Search for Enduring Values in Mexico's Modernization".The Wall Street Journal. 27/05/1994. 